Syntax Literate: Jurnal Ilmiah Indonesia p-ISSN: 2541-0849

e-ISSN: 2548-1398

Vol. 6, No. 1, Januari 2021

\title{
ANALISIS PENGELOLAAN HUTAN KEMASYARAKATAN (HKM) DI KABUPATEN LOMBOK TIMUR TERHADAP PENDAPATAN DAERAH
}

\author{
Boby Cipta Perdana, Saefuddin Baharsyah, M. Risky Syahputra dan Riski Adi \\ Dian Danu \\ Pondok Aren, Tangerang Selatan, Banten, Indonesia \\ Email: bobyperdana85@gmail.com, 2302190172.saefuddinbaharsyah@gmail.com, \\ Riskysyah162@gmail.com dan adiriski120@gmail.com
}

\begin{abstract}
This paper aims to analyze the implementation of community forest management $(\mathrm{HKm})$ in East Lombok Regency and its impact on regional income and to describe the factors that influence community forest management activities in East Lombok Regency. This research method used a qualitative descriptive method based on data from the NTB Environment and Forestry Service and the East Lombok BPS Regency. The results showed that local income would increase if the community of HKm paid a provision fee for forest products in accordance with the provisions of the law, and the success of the community in managing HKm was influenced by the factors of the suitability of program results with the needs of the community, the target of the Community Forest Management $(\mathrm{HKm})$ program, and assistance in managing community forests $(\mathrm{HKm})$ by local organizations.
\end{abstract}

Keywords: forest management; community forest; regional income

\begin{abstract}
Abstrak
Penelitian ini memiliki tujuan guna menganalisis pelaksanaan pengelolaan Hutan Kemasyarakatan $(\mathrm{HKm})$ di Kabupaten Lombok Timur dan dampaknya terhadap pendapatan daerah serta mendeskripsikan faktor yang mempengaruhi aktivitas pengelolaan Hutan Kemasyarakatan (HKm) yang ada di Kabupaten Lombok Timur. Metode penelitian ini menggunakan metode deskriptif kualitatif dengan berpedoman pada data dari Dinas Lingkungan Hidup dan Kehutanan NTB serta BPS Kabupaten Lombok Timur. Hasil penelitian menunjukkan bahwa pendapatan daerah akan bertambah apabila masyarakat pengelola $\mathrm{HKm}$ membayar biaya provisi atas hasil hutan sesuai dengan ketentuan undang-undang, dan keberhasilan masyarakat dalam mengelola $\mathrm{HKm}$ dipengaruhi oleh faktor kesesuaian hasil program dengan kebutuhan masyarakat pengelola, sasaran program pengelolaan Hutan Kemasyarakatan $(\mathrm{HKm})$, dan pendampingan pengelolaan Hutan Kemasyarakatan $(\mathrm{HKm})$ oleh organisasi setempat.
\end{abstract}

Kata Kunci: pengelolaan hutan; hutan kemasyarakatan (hkm); pendapatan daerah.

Coresponden Author

Email: bobyperdana85@gmail.com Artikel dengan akses terbuka dibawah lisensi 
Boby Cipta Perdana, Saefuddin Baharsyah, M. Risky Syahputra dan Riski Adi Dian Danu

\section{Pendahuluan}

Salah satu provinsi di Indonesia yang terdapat kekayaan alam potensial ada di NTB (Nusa Tenggara Barat. Terdiri dari 8 kabupaten dan 2 kotamadya, kekayaan alam yang dimiliki provinsi NTB salah satunya adalah sumber daya hutan. Dari delapan kabupaten tersebut, Kabupaten Lombok Timur memiliki luas lahan hutan sebesar 680 ribu hektare, dimana 230-ribu hektare lahan kritisnya adalah hutan (DISLHK NTB, 2020). Di kabupaten tersebut, hutan adalah sumber penghasilan masyarakat di sekitarnya dengan memanfaatkan potensi yang dimiliki hutan tersebut. Salah satunya yaitu dengan mengelola Hutan Kemasyarakatan (HKm).

Ketetapan dari Menteri Kehutanan Indonesia Nomor P.88/Menhut-II/2014 perihal Hutan Kemasyarakatan, Pasal 1 Ayat 1 menyebutkan jika hutan kemasyarakatan (HKm) ialah hutam negara dengan pemanfaatannya guna meningkatkan warga sekitar. Hutan Kemasyarakatan $(\mathrm{HKm})$ murni menjadi hak masyarakat untuk memanfaatkan potensi hutan tersebut untuk sumber mata pencaharian (Kartila, Ichsan, \& Markum, 2018). Hal yang sama juga dijelaskan oleh Ayudanti, (2017) bahwa tujuan dari Hutan Kemasyarakatan (HKm) yaitu untuk mengembangkan kapasitas/kemampuan dan memberikan akses masyarakat sekitar hutan mengelola hutan secara lestari agar terjamin ketersediaan lapangan pekerjaan untuk masyarakat sekitar hutan sehingga bisa mengurangi pengangguran atau mengurangi permasalahan sosial dan ekonomi yang ada di daerah tersebut. Tentu saja hal ini bisa menjadi upaya untuk mengurangi tingkat kemiskinan masyarakat di sekitar hutan. Namun pada kenyataannya pemanfaatan Hutan Kemasyarakatan $(\mathrm{HKm})$ masih menghadapi beberapa masalah di antaranya masih kurang ketatnya kebijakan tentang pemanfaatan hutan sehingga semakin banyak kerusakan sumber daya hutan yang diakibatkan karena eksploitasi, serta pendapatan masyarakat yang menurun karena semakin sulit dalam mengembangkan dan memanfaatkan sumber daya hutan akibat eksploitasi tersebut (Retnowathi, 2015).

Sulitnya mengembangkan potensi sumber daya hutan juga dikarenakan rendahnya kapasitas sumber daya manusianya (rendahnya tingkat pendidikan dan informasi) sehingga akses masyarakat terhadap pemanfaatan ekonomi hutan juga rendah yang mana ini berkaitan dengan angka kemiskinan di Kabupaten Lombok Timur. Data dari BPS Kabupaten Lombok Timur mencatat tahun 2017 tingkat warga miskin sejumlah 18,28\%, selang satu tahun, tepatnya 2018, warga miskin sebesar 16,55\%, dan pada tahun 2019 persentase penduduk miskin di Lombok Timur sebesar 16,15\%. Hal ini dapat disimpulkan bahwa pada 3 tahun terakhir persentase penduduk miskin di Kabupaten Lombok Timur mengalami penurunan. Namun, keadaan yang sebaliknya terjadi pada indeks pertumbuhan perekonomiannya. Pada tahun 2017 Kabupaten Lombol Timur menghasilkan PDRB (Produk Domestik Regional Bruto) sebesar 6,25\%. Pada tahun 2018 menurun drastis menjadi 3,36\% dan akhirnya pada tahun 2019 mengalami kenaikan menjadi 4,68\% (Badan Pusat Statistik Kabupaten Lombok Timur, 2020). Agar pendapatan daerah terus meningkat secara dinamis dan signifikan, diperlukan adanya pengelolaan Hutan Kemasyarakatan $(\mathrm{HKm})$ yang baik dan secara konsisten agar hutan 
dapat terjaga dan lestari serta menghasilkan input dan output yang seimbang. Karena masyarakat sekitar hutan masih mengandalkan hasil hutan sebagai sumber pendapatan. Sehingga apabila terkelola dengan baik, dapat meningkatkan pendapatan masyarakat sekitar hutan secara tidak langsung pun bisa memaksimalkan penghasilan daerah di wilayah tersebut (Hadi, 2018).

Pada penelitian terdahulu yang dilakukan oleh Prasetyo, dkk (2017) disebutkan bahwa sumber penerimaan daerah yang berasal dari sektor kehutanan berasal dari pihak ketiga yang membayar retribusi dari pengelolaan hutan tersebut. Pihak ketiga yang dimaksud adalah anggota masyarakat antara lain orang/pribadi, kelompok/organisasi, badan usaha swasta, BUMN dan Instansi Pemerintah yang mengelola hutan atau menjadi kontraktor dalam suatu proyek hutan. Lain dari penelitian yang dilakukan oleh Siburian (2018) menyebutkan bahwa kontribusi sumber daya hutan yang diperoleh pemerintah Kabupaten Manokwari berasal dari bagi hasil kegiatan IUPHHK-HA (Izin Usaha Pemanfaatan Hasil Hutan Kayu dalam Hutan Alam) yang dalam pemanfaatannya dibagi untuk pemerintah pusat $40 \%$ dan daerah penghasil $60 \%$ untuk kemudian digunakan untuk merehabilitasi hutan di daerah tersebut. Besarnya penerimaan daerah melalui kegiatan IPHHK tergantung pada jenis kayu yang diambil dari hutan. Semakin mahal harga pasar kayu, semakin tinggi retribusi yang dikenakan terhadap jenis kayu tersebut.

Dari dua penelitian tentang pengelolaan hutan terhadap pendapatan daerah di atas, peneliti menemukan faktor pembeda dalam menganalisisnya. Peneliti pertama menganalisis kontribusi pengelolaan hutan terhadap pendapatan daerah melalui besaran retribusi dari pihak ketiga dan peneliti kedua menganalisis melalui besaran bagi hasil kegiatan izin usaha pemanfaatan hasil hutan. Maka, pada penelitian ini kami menganalisis sumbangsih dari hasil pengelolaan hutan terhadap pendapatan daerah Kabupaten Lombok Timur dengan menghitung provisi sumber daya hutan serta pengganti rugi tegakan berdasarkan ketetapan Menteri Lingkungan Hidup dan Kehutanan RI Nomor P.64/MENLHK/SETJEN/KUM.1/12/2017. Manfaat penelitian ini adalah sebagai ilustrasi hitungan pendapatan daerah yang diterima Kabupaten Lombok Timur dari sekor kehutanan yang dihitung dari provisi yang diterima, sehingga dapat dijadikan sebagai salah satu alternatif untuk meningkatkan penerimaan daerah yang dapat pula membantu mengurangi tingkat kemiskinan. Lebih lanjut penelitian ini bertujuan untuk mengetahui tata kelola hutan kemasyarakatan di Kabupaten Lombok Timur terhadap pendapatan daerah beserta apa saja faktor yang mempengaruhi pengelolaannya.

\section{Metode Penelitian}

Metodologi penelitian ini menggunakan metode penelitian deskriptif kualitatif, yaitu sebuah kajian yang berusaha untuk menjelaskan data secara natural yang diperoleh melalui kata atau kalimat penjelasan kualitatif (Sugiyono, 2015). Jenis data yang digunakan dalam penelitian ini adalah data sekunder yang meliputi: 1) Data luas lahan hutan di Kabupaten Lombok Timur (DISLHK NTB) tahun 2020; 2) Data Nama 
Boby Cipta Perdana, Saefuddin Baharsyah, M. Risky Syahputra dan Riski Adi Dian Danu

Kelompok dan Luas Hutan Kemasyarakatan (DISLHK NTB) tahun 2009-2018; 3) Data persentase penduduk miskin di Kabupaten Lombok Timur (Badan Pusat Statistik Kabupaten Lombok Timur) tahun 2017-2019; 4) Data indeks pertumbuhan perekonomian Kabupaten Lombok Timur (Badan Pusat Statistik Kabupaten Lombok Timur) tahun 2017-2019; 5) Data Penetapan harga patokan hasil hutan (Penentuan Harga Patokan Hasil Hutan guna Perhitungan Provisi Sumber Daya Hutan dan Ganti Rugi Tegakan).

\section{Hasil dan Pembahasan}

\section{A. Pengelolaan Hutan Kemasyarakatan (HKm) di Lombok Timur}

Lombok Timur ialah satu dari beberapa kabuaten yang ada di NTB dengan luas wilayahnya sebesar $1.605,55 \mathrm{~km} 2$ dengan populasi sebanyak 1.105 .582 jiwa. Menilik topografi yang dimiliki oleh Lombok Timur, wilayah ini terletak pada ketinggian 0-3.726 mdpl. Kemiringan lahan bervariasi mulai dari 0 sampai dengan $>40 \%$, dengan iklim basah tropis dan kering, serta memiliki dua musim yaitu penghujan dan kemarau. Lombok Timur juga memiliki lahan hutan sebesar 680.620 hektare (Kabupaten Lombok Timur, Wikipedia) dan tercatat memiliki lima Hutan Kemasyarakatan $(\mathrm{HKm})$ yang dikelola dan sudah memiliki ijin (terdaftar) resmi. Tiap-tiap hutan tersebut dikelola oleh lima kelompok, di antaranya Wana Lestari, Lembah Sempager, Sekaroh (Jaya dan Maju), dan Dongo Baru.

\section{Hutan Kemasyarakatan (HKm) Desa Dara Kunci (Wana Lestari)}

Desa Dara Kunci adalah satu dari beberapa desa yang ada Kecamatan Sambelia, Kabupaten Lombok Timur yang luas wilayahnya sebesar 3,52 km2 dari seluruh wilayah Kecamatan Sambelia. Desa Dara Kunci terletak pada ketinggian 40 mdpl, terletak di dekat pantai sekaligus hutan, serta dipengaruhi oleh 2 musim yaitu kemarau dan hujan. Sebagian besar penduduk bermata pencaharian sebagai petani dan buruh tani. Selain itu, sebagian penduduk juga berprofesi sebagai pedagang, pengrajin dan PNS (Jayawinangun, R., Saputro, Bayu., 2019). Pelaksanaan pengelolaan Hutan Kemasyarakatan (HKm) mengacu pada Perda Nomor 6 tahun 2004 perihal ketentuan pemberlakuan dan pelaksanaan hutam masyarakat Provinsi Nusa Tenggara Barat. Pengelolaan Hutan Kemasyarakatan $(\mathrm{HKm})$ bisa tercapai apabila masyarakat yang mengelola hutan bisa melaksanakan kelola hutan sebaik mungkin agar memberi dampak positif bagi perekonomian maupun manfaat alam dengan terjaganya fungsi hutan hingga fungsi tata air di lingkungan hutan tersebut. Pengelolaan hutan tentu saja harus mengetahui kondisi atau proporsi tanaman di lahan Hutan Kemasyarakatan ( $\mathrm{HKm})$, dimana porsi tanaman keras sebanyak $60 \%$ dan tanaman pangan sebesar 40\%. Hutan Kemasyarakatan (HKm) Desa

Dara Kunci menerapkan tanaman multi purpose tree species atau tanaman multi fungsi seperti jambu mete, asam, palawija, dan srikaya. Awal pengelolaannya hasil tanaman tersebut hanya untuk memenuhi kebutuhan 
sehari-hari. Tapi lambat laun, hasil dari pengelolaan Hutan Kemasyarakatan (HKm) di Desa Dara Kunci bisa digunakan untuk membayar biaya pendidikan anak-anak mereka hingga ke jenjang perguruan tinggi.

Setelah berkembangnya hasil dari pengelolaan Hutan Kemasyarakatan (HKm) Desa Dara Kunci, Dinas Lingkungan Hidup dan Kehutanan Nusa Tenggara Barat memberikan pelatihan kepada warga Desa Dara Kunci agar lebih siap dalam kemampuan, tanggung jawab, dan kemauan dalam pengelolaan Hutan Kemasyarakatan (HKm). Pelatihan yang telah dilakukan di Desa Dara Kunci khususnya untuk kelompok pengelola Hutan Kemasyarakatan (HKm) Wana Lestari adalah pelatihan administrasi kelompok, pembibitan, dan pengelolaan setelah panen/pasca panen (Susanti AS, Purnaweni, \& Kismartini, 2018).

2. Hutan Kemasyarakatan (HKm) Desa Gunung Malang (Lembah Sempager)

Desa Gunung Malang ada di Kecamatan Pringgabaya Kabupaten Lombok Timur, memiliki wilayah yang luasnya sekitar $40 \mathrm{~km} 2$. Mayoritas penduduknya tidak bekerja, dimana masyarakat dengan pekerjaan berkebun atau bertani memiliki persentase hampir $21 \%$ dan sisanya merupakan pegawai negeri, karyawan swasta, pelajar dan lain-lain.

Kelompok pengelola Hutan Kemasyaratakan (HKm) di desa Gunung Malang adalah Lembah Sempager, dengan jumlah anggota kelompok yang 187 orang. Luas Hutan Kemasyarakatan (HKm) Lembah Sempager adalah 360 hektare dan sudah memiliki izin mengelola sejak tahun 2013 dengan nomor 188.45/249/Hutbun/2013 tanggal 24 Mei 2013 (DISLHK NTB, 2018). Dengan terbitnya izin untuk mengelola Hutan Kemasyarakatan (HKm) di Desa Gunung Malang, diharapkan dapat membantu memperbaiki kondisi ekonomi masyarakat sekitar hutan atau masyarakat pengelola. Pengelolaan Hutan Kemasyarakatan $(\mathrm{HKm})$ yang baik dapat tercapai bila masyarakat melaksanakan kelola hutan dengan baik dan berkelanjutan sehingga dapat memberikan manfaat ekonomi maupun alam, yang kemudian hasilnya dapat digunakan untuk memenuhi kebutuhan masyarakat setempat dan menyekolahkan anak-anak di Desa Gunung Malang.

Hasil Hutan Kemasyarakatan (HKm) Lembah Sempager yang dikelola antara lain kayu (mahoni, sonokeling, klokos udang, elar, gmelina) dan bukan kayu (padi, empon-empon, jagung, bawang, singkong, ubi jalar, dan umbiumbian lain). Hasil hutan ini akan sangat menguntungkan masyarakat pengelola apabila dijual dan akan memberikan pemasukan daerah karena masyarakat harus membayar pungutan provisi. Namun pada beberapa waktu terakhir, terjadi pembakaran hutan untuk pembukaan lahan perkebunan atau pertanian. Pada tahun 2019 lalu, setidaknya 100 hektare Hutan Kemasyarakatan $(\mathrm{HKm})$ habis terbakar. Terbakarnya hutan tersebut disinyalir karena warga salah mengartikan perubahan fungsi Hutan Produksi Terbatas (HPT) atau Hutan Lindung (HL) dan malah mengalihfungsikannya menjadi 
Boby Cipta Perdana, Saefuddin Baharsyah, M. Risky Syahputra dan Riski Adi Dian Danu

perkebunan (Website Resmi Desa Gunung Malang Kecamatan Pringgabaya Kabupaten Lombok Timur).

3. Hutan Kemasyarakatan (HKm) Desa Sekaroh (Sekaroh Jaya dan Sekaroh Maju)

Desa Sekaroh terletak di Kecamatan Jerowaru Kabupaten Lombok Timur, memiliki dua kelompok pengelola Hutan Kemasyaratakan (HKm) antara lain Sekaroh Jaya dengan luas Hutan Kemasyarakatan (HKm) yang dikelola adalah 234,39 Ha serta sudah memiliki izin mengelola sejak tahun 2013 dengan nomor izin pengelolaan 188.45/231.b/Hutbun/2013 dan Sekaroh Maju dengan luas Hutan Kemasyarakatan (HKm) yang dikelola adalah 309,69 Ha 360 serta sudah memiliki izin mengelola sejak tahun 2012 dengan nomor izin pengelolaan 188.45/443/Hutbun/2012 (DISLHK NTB, 2018).

Tanaman kehutanan yang dipilih pada Hutan Kemasyarakatan $(\mathrm{HKm})$ di Desa Sekaroh merupakan tipe yang memang diakusi mampu hidup serta dapat beraklimatisasi terhadap situasi biofisik Hutan Lindung Sekaroh. Varietas tanaman itu, antara lain pohon mahoni (Swietenia macrophylla), pohon imbe/mimba (Azadirachta indica), pohon trembesi (Albizia saman) serta pohon khaya (Khaya anthotheca). Selain tanaman kehutanan, kegiatan pengelolaan Hutan Kemasyarakatan (HKm) Sekaroh Jaya dan Sekaroh Maju pun turut bercocok tanam bermacam buah. Varietas yang umum dipilih masyarakat, terdiri atas manga, nangka, asam, dan srikaya. Ketika kemarau tiba, pohon asam ialah varietas yang nilai jual relatif tinggi ketimbang buah lain sehingga daerah Sekaroh dikenal sebagai penghasil asam di kawasan Nusa Tenggara Barat.

\section{Hutan Kemasyarakatan (HKm) Desa Sapit (Dongo Baru)}

Desa Sapit luas wilayahnya sebesar 1.440,7 hektar dengan jumlah anggota kelompok yang mengelola Hutan Kemasyarakatan (HKm) Dongo Baru sebanyak 722 orang pada tahun 2018. Luas Hutan Kemasyarakatan (HKm) Dongo Baru sebesar 450 hektar dan sudah memiliki izin mengelola sejak tahun 2016 (DISLHK NTB, 2018).

Desa Sapit merupakan daerah yang memiliki tingkat kemiskinan cukup signifikan karena rendahnya pendapatan masyarakat. Salah satu penyebabnya adalah karena adanya kerusakan hutan yang tentu saja memengaruhi totak keseluruhan sumber daya alam, khususnya hutan yang bisa difungsikan warga sekitar. Kerusakan hutan ini disebabkan karena masih banyak program kehutanan yang tidak terkontrol atau program kehutanan yang silih berganti sehingga hutan menjadi tidak terurus dan masyarakat menjadi tidak bisa mengambil manfaat yang didapat dari sumber daya hutan. Bahkan tidak jarang terjadi pencurian kayu oleh oknum-oknum tidak bertanggung jawab yang menyebabkan masyarakat menjadi semakin sulit memperoleh pendapatan dari hasil hutan. Namun setelah diberikan izin mengelola Hutan Kemasyarakatan 
(HKm) Dongo Baru, diharapkan dapat meningkatkan pendapatan masyarakat dan meningkatkan kesejahteraan dengan mengelola hutan. Areal pengelolaan Hutan Kemasyarakatan (HKm) Dongo Baru dibagi menjadi enam blok, di antaranya adalah blok Pidana seluas 140 hektare, blok Serata seluas 100 hektare, blok Dupe seluas 60 hektare, blok Sakan seluas 64,5 hektare, blok Pesuse seluas 40 hektare, serta blok Lembak dengan luas 50 hektare. Ke-enam blok tersebut dikelola oleh Gabungan Kelompok Petani (Gapoktan) yang bernama Dongo Baru.

Pengelolaan hutan diawali dengan pembentukan kelompok yang kemudian diberi nama Dongo Baru. Selanjutnya menyusun peraturan pengelolaan Hutan Kemasyarakatan (HKm) atas kesepakatan bersama. Peraturan inilah yang berhasil mengurangi dan menekan kasus pencurian kayu serta kerusakan hutan. Selain itu, setelah disepakati peraturan pengelolaan hutan, sistem penanaman pohon diperbaiki dengan bercocok tanam tumpang sari, pohon tegakan, dan tanaman yang memiliki banyak kegunaan lainnya yang telah tumbuh dengan baik dan subur. Dampak dari adanya pengelolaan Hutan Kemasyarakatan (HKm) Dongo Baru ini adalah betambahnya ketersediaan air melalui beberapa mata air yang ada di desa tersebut seperti mata air Pancor Jaman, Pesusa, Sebau, dan lain-lain. Hasil hutan yang dikelola antara lain adalah kayu (mahoni, sonokeling, gmelina, elar, klokos udang) dan bukan kayu (jagung, empon-empon, padi, ashitaba, ubi jalar, singkong, bawang, dan sayur mayur). Hasil lain dari pohon serba guna, misalnya pohon rambutan, nangka, durian, kopi, cengkeh, kakao, jeruk, jambu, pisang, hingga mangga. Dari hasil hutan tersebut, dijual oleh masyarakat pengelola untuk memperoleh pendapatan yang bisa digunakan untuk menyambung hidup dan menambah kesejahteraan mereka, dari memenuhi kebutuhan primer hingga sekunder (Hadi, 2018).

\section{B. Faktor yang Mempengaruhi Pengelolaan Hutan Kemasyarakatan (HKm) Kabupaten Lombok Timur}

Secara umum faktor-faktor yang mempengaruhi kegiatan pengelolaan Hutan Kemasyarakatan (HKm) di Kabupaten Lombok Timur antara lain:

\section{Kesesuaian hasil program dengan kebutuhan masyarakat pengelola}

Motivasi dari masyarakat pengelola kawasan Hutan Kemasyarakatan (HKm) adalah mereka hanya ingin mendapatkan lahan yang dapat dikelola sehingga menghasilkan sesuatu yang bernilai jual untuk peningkatan kesejahteraan hidup. Selain itu belum terdapat pengevaluasian agenda dari pemerintah. Perihal peragaman tumbuhan bagi area Hutan Kemasyarakatan (HKm), bibit dari pemerintah datangnya saat menjelang musim kemarau, sehingga saat bibit tersebut ditanam banyak yang gagal (Susanti AS et al., 2018).

\section{Sasaran Program Pengelolaan Hutan Kemasyarakatan (HKm)}


Boby Cipta Perdana, Saefuddin Baharsyah, M. Risky Syahputra dan Riski Adi Dian Danu

Program pengelolaan Hutan Kemasyarakatan (HKm) yang bertujuan guna meningkatkan warga sekitar hutan agar terbebas dari kemiskinan masih terdapat beberapa yang tidak tepat sasaran sehingga malah menyebabkan pemborosan tenaga, dana, dan waktu untuk penyuluhan, pembelian pupuk dan bibit, pelaksanaan program pengelolaan hutan. Beberapa masyarakat juga kewalahan dalam mengelola sumber daya hutan karena rendahnya tingkat pendidikan mereka sehingga pengembangan potensi masyarakat tidak optimal. Faktor ini membutuhkan peran dan keberadaan Dinas Lingkungan Hidup dan Kehutanan untuk melakukan identifikasi yang lebih jelas dan rinci lagi tentang kebutuhan dan keberadaan masyarakat terhadap manfaat sumber daya hutan agar proses pengurusan izin, hak, maupun kolaborasi menjadi lebih mudah untuk dilakukan (Susanti AS et al., 2018).

\section{Pendampingan pengelolaan Hutan Kemasyarakatan $(\mathbf{H K m})$ oleh organisasi setempat}

Pengelolaan Hutan Kemasyarakatan ( $\mathrm{HKm}$ ) sewajarnya didampingi oleh pelaksana teknis dari organisasi setempat yang menaungi pengelolaan hutan. Tentu saja kegiatan pendampingan ini membutuhkan sumber dana yang memadai. Namun, pada prakteknya sumber dana untuk pendampingan masih kurang memadai jika dibandingkan dengan luasnya areal Hutan Kemasyarakatan (HKm) di Kabupaten Lombok Timur yang mengakibatkan berkurangnya motivasi sumber daya manusia pelaksa teknis selaku yang mendapingi pelaksanaan pengelolaan hutan dan masyarakat pengelola sebagai pelaksana program (Susanti AS et al., 2018).

\section{Dampak Pengelolaan Hutan Kemasyarakatan (HKm) Kabupaten Lombok Timur terhadap Pendapatan Daerah}

Pendapatan daerah dari pengelolaan hutan berasal dari retribusi Provisi Sumber Daya Hutan (PSDH) sebagaimana diatur dalam ketetapan Menteri Lingkungan Hidup dan Kehutanan RI Nomor P.64/MENLHK/SETJEN/KUM.1/12/2017 perihal penentuan harga hasil hutan guna hitungan provisi sumber daya hutan serta pengganti rugi tegakan. Pada peraturan menteri tersebut dijelaskan bahwa PSDH (provisi sumber daya hutan), yaitu punggutan biaya yang dijadikan pengganti atas nilai intrinsik hasil hutan negara atau terhadap hasil hutan yang letaknya di kawasan hutan negara yang dipercadangkan guna alokasi pembangunan selain untuk bidang kehutanan. Provisi tersebut tentu saja masuk ke dalam pendapatan daerah, dalam hal ini pendapatan daerah Kabupaten Lombok Timur dari sektor Hutan Kemasyarakatan (HKm) karena tujuan dari ditetapkannya harga patokan hasil hutan adalah untuk mengoptimalkan penerimaan negara pada umumnya, dan penerimaan daerah pada khususnya, atas hasil kehutanan serta memberi jaminan atas tata kelola hutan 
produksi melalui sektor lingkungan, sosial, maupun perekonomian (Permen-LHKNo.-P.64-Tahun-2017-Harga-Patokan.pdf).

Melihat dari penetapan harga patokan hasil hutan dalam peraturan menteri tersebut, cara menghitung provisi yaitu berdasarkan formula tarif yang dapat diketahui di dalam lampiran peraturan menteri yang telah disebutkan, dikalikan ke harga tolok ukur PSDH, dan dikalikan lagi ke volume hasil hutan. Tarif yang dimaksud di dalam rumus perhitungan provisi adalah tarif yang tercantum di ketetapan Pemerintah No. 12 Tahun 2014 perihal Jenis dan Tarif Penerimaan Negara Bukan Pajak yang diberlakukan bagi Kementerian Kehutanan, dimana tarif untuk hasil hutan kayu sebesar 10\% dan tarif untuk hasil hutan bukan kayu sebesar 6\% (PP No.12 tahun 2014).

Pada studi ini memberikan contoh perhitungan PSDH dengan menghitung volume hasil kelima Hutan Kemasyarakatan $(\mathrm{HKm})$ di Kabupaten Lombok Timur per $\mathrm{m}^{3}$ untuk hasil kayu dan per 1 ton untuk volume hasil bukan kayu, yang kemudian akan ditarik analisis hasil pengelolaan Hutan Kemasyarakatan (HKm) terhadap pendapatan daerah melalui pembayaran provisi.

Bertolok ukur ke ketetapan Menteri Lingkungan Hidup dan Kehutanan RI Nomor P.64/MENLHK/SETJEN/KUM.1/12/2017 perihal Penetapan Harga Patokan Hasil Hutan guna Perhitungan Provisi Sumber Daya Hutan dan Ganti Rugi Tegakan dan Peraturan Pemerintah (PP) No. 12 Tahun 2014 tentang Jenis Dan Tarif Penerimaan Negara Bukan Pajak yang diberlakukan ke Kementerian Kehutanan, maka hitungan Provisi Sumber Daya Hutan (PSDH) di Hutan Kemasyarakatan (HKm) Kabupaten Lombok Timur adalah sebagai berikut:

Tabel 1

PSDH Hutan Kemasyarakatan (HKm) Wana Lestari (Desa Dara Kunci)

\begin{tabular}{lccccc}
$\begin{array}{c}\text { Hasil } \\
\text { Hutan }\end{array}$ & Tarif & $\begin{array}{c}\text { Volume } \\
\text { Hasil } \\
\text { Hutan }\end{array}$ & $\begin{array}{c}\text { Harga } \\
\text { Patokan } \\
\text { PSDH }\end{array}$ & Jumlah \\
\hline Bukan & & & & & \\
Kayu: & & & & & \\
-Jambu & $6 \%$ & 1 ton & Rp500.000 & Rp 30.000 \\
$\quad$ mete & $6 \%$ & 1 ton & Rp300.000 & Rp 18.000 \\
- Asam & $6 \%$ & 1 ton & Rp500.000 & Rp 30.000 \\
-Palawija & $6 \%$ & 1 ton & Rp500.000 & Rp 30.000 \\
- Srikaya & & & & & \\
\hline
\end{tabular}

Sumber: Permen-LHK-No.-P.64-Tahun-2017-Harga-Patokan.pdf

Dikarenakan Hutan Kemasyarakatan (HKm) Wana Lestari di Desa Dara Kunci menerapkan tanaman multi purpose tree species atau tanaman multi fungsi maka di dalam tabel terlulis hasil hutan bukan kayu. Di tabel tersebut simpulan menyatakan jika apabila Hutan Kemasyarakatan (HKm) Wana Lestari menghasilkan hasil hutan bukan kayu sebanyak 1 ton per-jenis dalam sekali panen maka Desa Dara Kunci sudah turut menyumbang pendapatan daerah Kabupaten 
Boby Cipta Perdana, Saefuddin Baharsyah, M. Risky Syahputra dan Riski Adi Dian Danu

Lombok Timur sebesar Rp108.000 sekali panen melalui pungutan provisi sumber daya hutan tersebut, dan berlaku kelipatannya serta telah meningkatkan kesejahteraan hidup masyarakat pengelola itu sendiri dengan menikmati hasil hutan tersebut.

Tabel 2

PSDH Hutan Kemasyarakatan (HKm) Lembah Sempager (Desa Gunung Malang)

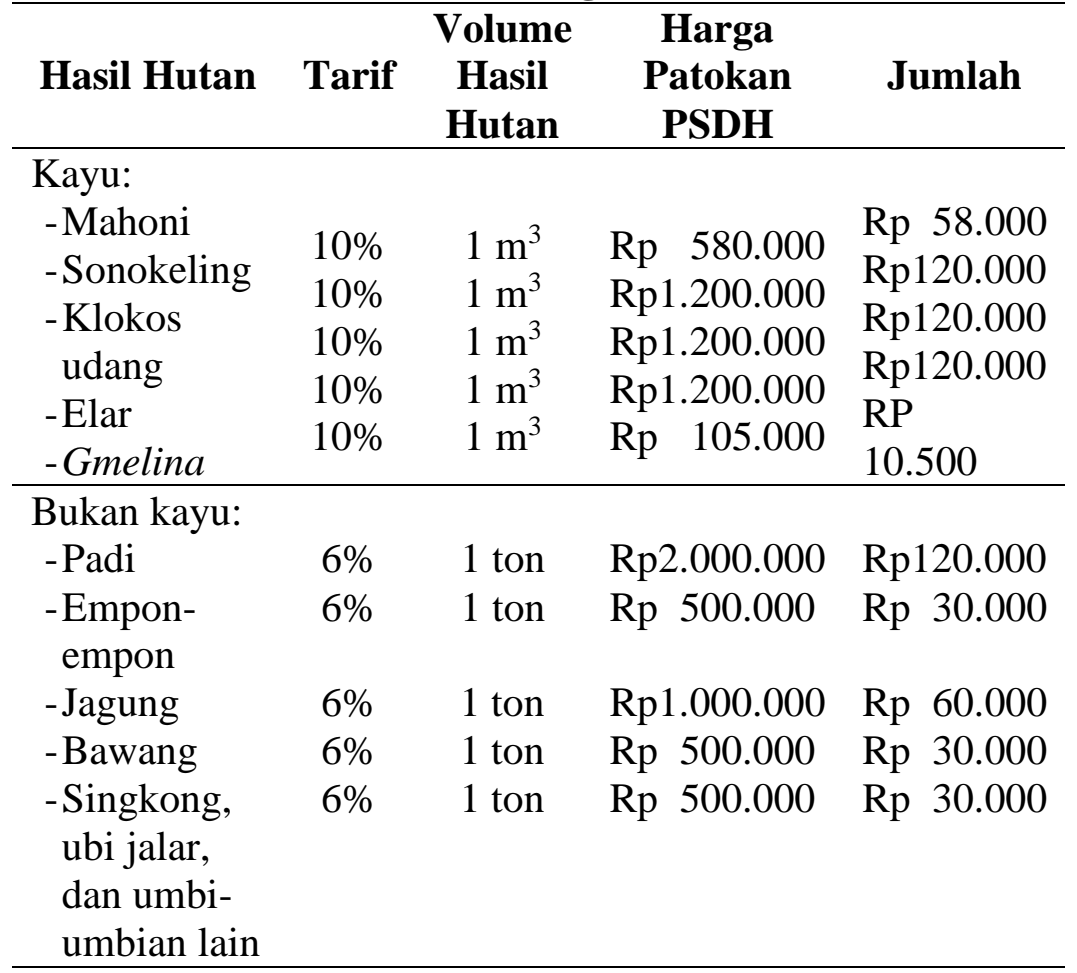

Total $\operatorname{Rp} 698.500$

Berdasar penjelasan di Tabel 2 simpulan yang didapat menyatakan apabila Hutan Kemasyarakatan (HKm) Lembah Sempager menghasilkan hasil hutan kayu per $\mathrm{m}^{3}$ setiap jenisnya dan hasil hutan bukan kayu sebanyak per ton setiap jenisnya maka Desa Gunung Malang sudah turut menyumbang pendapatan daerah Kabupaten Lombok Timur sebesar Rp698.500 sekali panen melalui pungutan provisi sumber daya hutan tersebut, berlaku kelipatannya dan tentunya kesejahteraan hidup masyarakat pengelola itu sendiri ikut terangkat dengan menikmati hasil hutan tersebut. 
Tabel 3

PSDH Hutan Kemasyarakatan (HKm) Sekaroh Jaya dan Sekaroh Maju (Desa Sekaroh)

\begin{tabular}{lcllll}
\hline Hasil Hutan & Tarif & $\begin{array}{c}\text { Volume } \\
\text { Hasil } \\
\text { Hutan }\end{array}$ & $\begin{array}{c}\text { Harga } \\
\text { Patokan } \\
\text { PSDH }\end{array}$ & Jumlah \\
\hline Kayu: & & & & & \\
-Mahoni & $10 \%$ & $1 \mathrm{~m}^{3}$ & $\mathrm{Rp} 580.000$ & $\mathrm{Rp} \mathrm{58.000}$ \\
-Mimba & $10 \%$ & $1 \mathrm{~m}^{3}$ & $\mathrm{Rp} 1.200 .000$ & $\mathrm{Rp} 120.000$ \\
-Trembesi & $10 \%$ & $1 \mathrm{~m}^{3}$ & $\mathrm{Rp} 1.200 .000$ & $\mathrm{Rp} 120.000$ \\
-Khaya & $10 \%$ & $1 \mathrm{~m}^{3}$ & $\mathrm{Rp} 1.200 .000$ & $\mathrm{Rp} 120.000$ \\
\hline Bukan kayu: & & & & & \\
-Srikaya & $6 \%$ & 1 ton & $\mathrm{Rp} 500.000$ & $\mathrm{Rp} 30.000$ \\
-Mangga & $6 \%$ & 1 ton & $\mathrm{Rp} \mathrm{500.000}$ & $\mathrm{Rp} \mathrm{30.000}$ \\
-Nangka & $6 \%$ & 1 ton & $\mathrm{Rp} 2.000 .000$ & $\mathrm{Rp} 120.000$ \\
-Asam & $6 \%$ & 1 ton & $\mathrm{Rp} 300.000$ & $\mathrm{Rp} 18.000$ \\
\hline & & & & Total & $\mathrm{Rp} 616.000$ \\
\hline
\end{tabular}

Berdasar penjelasan di Tabel 3, simpulan yang didapat menjelaskan apabila Hutan Kemasyarakatan (HKm) Sekaroh Jaya dan Sekaroh Maju menghasilkan hasil hutan kayu sekali panen per $\mathrm{m}^{3}$ tiap jenisnya dan hasil hutan bukan kayu sebanyak 1 ton per-jenisnya maka Desa Sekaroh sudah ikut menyumbang pendapatan daerah Kabupaten Lombok Timur sebesar Rp616.000 sekali panen melalui pungutan provisi sumber daya hutan tersebut, dan berlaku kelipatannya. Banyaknya macam sumber daya hutan yang dikelola oleh masyarakat Desa Sekaroh menyebabkan tingginya hasil perhitungan provisi sumber daya hutan pula. Dengan hal ini seharusnya perekonomian masyarakat pengelola mengalami peningkatan karena memperoleh hasil dari pengelolaan hutan tersebut. 
Boby Cipta Perdana, Saefuddin Baharsyah, M. Risky Syahputra dan Riski Adi Dian Danu

Tabel 4

PSDH Hutan Kemasyarakatan (HKm) Dongo Baru (Desa Sapit)

\begin{tabular}{|c|c|c|c|c|}
\hline Hasil Hutan & Tarif & $\begin{array}{c}\text { Volume } \\
\text { Hasil Hutan }\end{array}$ & $\begin{array}{c}\text { Harga } \\
\text { Patokan PSDH }\end{array}$ & Jumlah \\
\hline \multicolumn{5}{|l|}{ Kayu: } \\
\hline -Mahoni & $10 \%$ & $1 \mathrm{~m}^{3}$ & Rp 580.000 & Rp58.000 \\
\hline -Sonokeling & $10 \%$ & $1 \mathrm{~m}^{3}$ & Rp1.200.000 & Rp120.000 \\
\hline - Gmelina & $10 \%$ & $1 \mathrm{~m}^{3}$ & $\operatorname{Rp} 105.000$ & Rp10.500 \\
\hline -Elar & $10 \%$ & $1 \mathrm{~m}^{3}$ & Rp1.200.000 & Rp120.000 \\
\hline $\begin{array}{l}\text { - Klokos } \\
\text { udang }\end{array}$ & $10 \%$ & $1 \mathrm{~m}^{3}$ & Rp1.200.000 & Rp120.000 \\
\hline \multicolumn{5}{|l|}{ Bukan kayu: } \\
\hline -Jagung & $6 \%$ & 1 ton & Rp1.000.000 & $\operatorname{Rp} 60.000$ \\
\hline $\begin{array}{l}\text {-Empon- } \\
\text { empon }\end{array}$ & $6 \%$ & 1 ton & $\mathrm{Rp} \quad 500.000$ & $\mathrm{Rp} 30.000$ \\
\hline -Padi & $6 \%$ & 1 ton & Rp2.000.000 & Rp120.000 \\
\hline -Ashitaba & $6 \%$ & 1 ton & Rp1.000.000 & Rp 60.000 \\
\hline -Bawang & $6 \%$ & 1 ton & $\mathrm{Rp} \quad 500.000$ & $\mathrm{Rp} 30.000$ \\
\hline $\begin{array}{l}\text {-Singkong, } \\
\text { ubi jalar, } \\
\text { dan umbi- } \\
\text { umbian lain }\end{array}$ & $6 \%$ & 1 ton & $\mathrm{Rp} \quad 500.000$ & $\mathrm{Rp} 30.000$ \\
\hline -Rambutan & $6 \%$ & 1 ton & Rp 500.000 & Rp 30.000 \\
\hline -Nangka & $6 \%$ & 1 ton & Rp2.000.000 & Rp120.000 \\
\hline -Durian & $6 \%$ & 1 ton & Rp2.000.000 & Rp120.000 \\
\hline -Kopi & $6 \%$ & 1 ton & $\mathrm{Rp} \quad 450.000$ & Rp 27.000 \\
\hline -Cengkeh & $6 \%$ & 1 ton & Rp5.000.000 & Rp300.000 \\
\hline - Kakao & $6 \%$ & 1 ton & $\mathrm{Rp} 500.000$ & Rp 30.000 \\
\hline \multirow[t]{2}{*}{ - Jambu } & $6 \%$ & 1 ton & Rp 500.000 & Rp 30.000 \\
\hline & & & Total & Rp987.000 \\
\hline
\end{tabular}

Berdasarkan penjelasan di Tabel 4, simpulan yang didapat menyatakan apabila Hutan Kemasyarakatan (HKm) Dongo Baru menghasilkan hasil hutan kayu sekali panen per $\mathrm{m}^{3}$ tiap jenisnya dan hasil hutan bukan kayu sebanyak 1 ton perjenisnya maka Desa Sapit sudah ikut menyumbang pendapatan daerah Kabupaten Lombok Timur sebesar Rp987.000 sekali panen melalui pungutan provisi sumber daya hutan tersebut, dan berlaku kelipatannya. Dari keseluruhan Hutan Kemasyarakatan $(\mathrm{HKm})$ yang ada di Lombok Timur, Desa Sapit menyumbang provisi paling tinggi karena banyaknya macam sumber daya hutan yang dikelola. Maka sudah pasti perekonomian masyarakat pengelola mengalami peningkatan karena memperoleh hasil dari pengelolaan hutan tersebut dan pendapatan daerah juga ikut meningkat. 


\section{Kesimpulan}

Dari seluruh deskripsi tentang pengelolaan Hutan Kemasyarakatan (HKm) di Kabupaten Lombok Timur di atas, dapat ditarik kesimpulan bahwa HKm Wana Lestari di Desa Dara Kunci menerapkan tanaman multi purpose tree species atau tanaman multi fungsi sehingga hanya menghasilkan hasil hutan bukan kayu. Namun turut membantu pemasukan daerah sebesar Rp108.000 dihitung per ton hasil panen. Kedua, HKm Lembah Sempager menghasilkan Provisi Sumber Daya Hutan (PSDH) sebesar Rp698.500 melalui hasil hutan kayu per m3 setiap jenisnya dan hasil hutan bukan kayu sebanyak per ton setiap jenisnya. Ketiga, Hutan Kemasyarakatan (HKm) Sekaroh Jaya dan Sekaroh Maju membantu menyumbang pendapatan daerah sebesar Rp616.000 dengan hasil hutan kayu sekali panen per m3 tiap jenisnya dan hasil hutan bukan kayu sebanyak 1 ton per-jenisnya. Keempat, Hutan Kemasyarakatan (HKm) Dongo Baru menyumbang pendapatan daerah sebesar Rp987.000 dari hasil hutan kayu sekali panen per m3 tiap jenisnya dan hasil hutan bukan kayu sebanyak 1 ton per-jenisnya. Hal ini tentu saja sangat membantu meningkatkan perekonomian daerah melalui pendapatan daerah dari sektor Hutan Kemasyarakatan $(\mathrm{HKm})$. Sehingga berhasil atau tidaknya selama mengelola Hutan Kemasyarakatan $(\mathrm{HKm})$ di Kabupaten Lombok Timur sangat berpengaruh terhadap banyaknya pemasukan pendapatan daerah dari sektor Hutan Kemasyarakatan (HKm). Maka, agar kegiatan dan program pengelolaan Hutan Kemasyarakatan $(\mathrm{HKm})$ berjalan dengan baik dan maksimal harus memperhatikan faktor-faktor seperti: 1) kesesuaian hasil program dengan kebutuhan masyarakat pengelola, 2) sasaran program pengelolaan Hutan Kemasyarakatan (HKm), dan 3) pendampingan pengelolaan Hutan Kemasyarakatan $(\mathrm{HKm})$ oleh organisasi setempat. Dengan begitu kegiatan pengelolaan Hutan Kemasyarakatan (HKm) khususnya di Kabupaten Lombok Timur akan beroperasi secara optimal dan efisien. Tidak hanya itu, Hutan Kemasyarakatan (HKm) yang berhasil akan membantu pemerintah dalam mengentaskan kemiskinan yang masih ada di Kabupaten Lombok Timur. 
Boby Cipta Perdana, Saefuddin Baharsyah, M. Risky Syahputra dan Riski Adi Dian Danu

\section{BIBLIOGRAFI}

Ayudanti, Kiki. (2017). Analisis Efektivitas Hutan Kemasyarakatan dalam Meningkatkan Pendapatan dan Tingkat Konsumsi Masyarakat Menurut Perspektif Ekonomi Islam. Universitas Islam Negeri Raden Intan Lampung. Skripsi.

Badan Pusat Statistik Kabupaten Lombok Timur. (2018). Retrieved January 15, 2021, from https://lomboktimurkab.bps.go.id/indicator/23/37/1/persentase-pendudukmiskin.html

DISLHK NTB - Website Resmi Dinas Lingkungan Hidup dan Kehutanan Provinsi NTB. (n.d.). Retrieved January 15, 2021, from https://dislhk.ntbprov.go.id/

Hadi, Hasrul. (2018). Analisis Dampak Pengelolaan Hutan Kemasyarakatan (HKm) di Desa Sapit Kecamatan Suela Kabupaten Lombok Timur. Geodika: Jurnal Kajian Ilmu Dan Pendidikan Geografi, 2(1), 9-21.

Jayawinangun, R., Saputro, Bayu., Supriyanto. (2019). Hutan Kemasyarakatan Hidup Matinya Petani Miskin. In Nurhidayat Moenir Moh. Djauhari, Aftrinal S Lubis (Ed.), Journal of Chemical Information and Modeling (Cetakan Pe, Vol. 53). Bandung: IPB Press Printing, Bogor - Indonesia.

Kabupaten Lombok Timur-Wikipedia bahasa Indonesia, ensiklopedia bebas. (n.d.). Retrieved January 15, 2021, from: https://id.wikipedia.org/wiki/Kabupaten_Lombo k_Timur

Kartila, Nihad, Ichsan, Andi Chairil, \& Markum. (2018). Kontribusi Hasil Hutan Bukan Kayu Kemiri Terhadap Pendapatan Petani Hkm Tangga Desa Selengen. 1(2), 89100.

Permen-LHK-No.-P.64-Tahun-2017-Harga-Patokan.pdf. (n.d.).

PP No.12 tahun 2014. , 44 Journal for Research § (2019).

Prasetyo, Windu Adi., Budiani, Evi Sri., Arlita, Tuti. (2017). Kontribusi Sektor Kehutanan terhadap Pendapatan Asli Daerah (PAD) di Kabupaten Kuantan Singingi. 4(1), 72-76.

Retnowathi, Renny. (2015). HKm Menjadi Solusi Permasalahan Kehutanan, Diakses dari:hutankitarenny.blogspot.co.id/2015/01/hkm-menjadi-solusipermasalahan.htm

Siburian, Robert. (2018). Akses dan pengelolaan sumber daya hutan pada masyarakat lokal di Kabupaten Manokwari. Jurnal Masyarakat Dan Budaya, 20(3), 297-312.

Sugiyono. (2015). Metode Penelitian Kuantitatif Kualitatif dan R\&D. Bandung: Alfabeta. 
Analisis Pengelolaan Hutan Kemasyarakatan (HKm) di Kabupaten Lombok Timur terhadap Pendapatan Daerah

Susanti AS, Mey, Purnaweni, Hartuti, \& Kismartini, Kismartini. (2018). Analisis Program Hutan Kemasyarakatan $(\mathrm{HKm})$ di Desa Dara Kunci Kabupaten Lombok Timur Provinsi NTB. Jurnal Ilmiah Tata Sejuta STIA Mataram, 4(1), 1-12. https://doi.org/10.32666/tatasejuta.v4i1.48

Website Resmi Desa Gunung Malang Kecamatan Pringgabaya Kabupaten Lombok Timur. (2021). Retrieved January 15, 2021, from https://www.gunungmalangpringgabaya.desa.id/ 